\section{PRAXIOLOGIA MOTRIZ, TRABALHO PEDAGÓGICO E DIDÁTICA NA EDUCAÇÃO FÍSICA}

\author{
PRAXIOLOGÍA MOTRIZ, TRABAJO PEDAGÓGICO Y DIDÁCTICA EN LA \\ EDUCACIÓN FÍSICA
}

MOTOR PRAXIOLOGY, PEDAGOGICAL WORK AND DIDACTICS IN PHYSICAL EDUCATION

Daiane Dalla Nora*, Janaíne Welter*, Jaqueline Welter*, Elciana Buffon*, João Francisco Magno Ribas*
Palavras chave Educação Física. Educação. Pedagogia.

Palabras clave Educación Física. Educación. Pedagogía
Resumo: 0 estudo objetiva sistematizar aproximações entre a Praxiologia Motriz e a Pedagogia Histórico-Crítica, Crítico-Superadora na Educação Física. Nesta análise teórica será realizada a discussão de conceitos da Praxiologia Motriz relativos à lógica interna, com as características da Pedagogia Histórico-Crítica. Constata-se que a Praxiologia Motriz se constitui num aporte teórico imprescindível, pois aponta novos conhecimentos para trabalho pedagógico e da didática das manifestações da Cultura Corporal, consolidando cada vez mais a prática social da Educação Física.
Keywords Physical Education. Education. Pedagogy.

\begin{abstract}
The study aims at systematizing approximations between Motor Praxiology and Historical-Critical, Critical-Overcoming Pedagogy in Physical Education. This theoretical analysis will approach the concepts of Motor Praxiology regarding Internal Logic, with characteristics of Historical-Critical Pedagogy. Motor Praxiology is an essential theoretical framework because it points out new knowledge for pedagogical work and the didactics of the Body Culture manifestations, thus advancing the consolidation of the social practice of Physical Education.
\end{abstract}

*Universidade Federal de Santa Maria. Santa Maria, RS, Brasil. E-mail: dallanoradaiane@gmail.com

Recebido em: 07-06-2016 Aprovado em: 22-09-2016 (c) (1) () Licence 


\section{INTRODUÇÃO}

A Praxiologia Motriz é uma disciplina científica geradora de uma área do conhecimento específica que se dedica ao estudo das práticas motrizes. Há mais de quarenta anos, desde a sistematização de seus fundamentos teóricos e metodológicos, produzem-se investigações no campo da motricidade e das práticas lúdicas e esportivas. Como campo científico emergente, pertencente à área epistemológica da Ação Motriz, iniciou entre as décadas de 1960 e 1970 na Universidade René Descartes - Paris V, na França, sob a égide do Dr. Pierre Parlebas. A principal obra do autor, intitulada Jeux, Sports et Sociétés. Lexique de Praxéologie Motrice, foi publicada em 1999, reunindo as ideias centrais da teoria em forma de léxico. Essa área é conhecida também como Teoria da Ação Motriz, na qual a definição de Praxiologia Motriz é a "Ciência da Ação Motriz e especialmente das condições, modos de funcionamento e resultados de seu desenvolvimento" (PARLEBAS, 2001, p. 354).

A Ciência da Ação Motriz não se constitui numa abordagem da Educação Física, não se caracteriza como uma metodologia de ensino, mas, sim, como um conhecimento científico, criterioso e consistente atinente à lógica de funcionamento de jogos e esportes que produz novos e relevantes entendimentos dessas manifestações. A contribuição científica da Praxiologia Motriz tem se centrado em investigar aspectos estruturais das manifestações da Cultura Corporal, de onde emergem as ações motrizes. Desse modo, as práticas motrizes podem ser abordadas não só a partir de um olhar biomecânico ou biomédico, mas a partir de um objeto de estudo original que enfatiza a essência de tais manifestações para os sujeitos que as levam a cabo (RIBAS; OLIVEIRA, 2010; ARAÚJO; SOUZA; RIBAS, 2014).

Conhecimentos relacionados à Organização do Trabalho Pedagógico e da Didática, considerando o conhecimento Praxiológico, são de suma importância para a área e poderão elucidar questões como: Qual o papel da Praxiologia Motriz na Organização do Trabalho Pedagógico e da Didática? Como inserir os conceitos propostos por Pierre Parlebas relativos aos jogos e esportes nos distintos enfoques e concepções atuais na Educação Física brasileira e latino-americana?

Este ensaio é fruto dessas reflexões e da produção intelectual realizada no Grupo de Estudos Praxiológicos (GEP Brasil) e no Grupo de Pesquisa em Lazer e Formação de Professores, que procuram articular os conceitos de trabalho pedagógico e Praxiologia Motriz, bem como suas implicações didáticas da concepção pedagógica que tem orientado esses grupos. Neste estudo, objetiva-se sistematizar aproximações entre a Praxiologia Motriz e a Pedagogia Histórico-Crítica, a qual embasa a abordagem Crítico-Superadora na Educação Física. $O$ debate teórico se estrutura em três momentos: inicialmente, objetiva-se caracterizar 0 trabalho pedagógico e a didática; em seguida, apresentaremos os fundamentos da Praxiologia Motriz; e, posteriormente, estabeleceremos as aproximações da Praxiologia Motriz com a Pedagogia Histórico-Crítica/Crítico-Superadora.

\section{TRABALHO PEDAGÓGICO E A DIDÁTICA}

O trabalho pedagógico é uma prática social e, consequentemente, é influenciado pelas relações sociais, repercutindo no trabalho que é desenvolvido pelo professor. Isso faz com 
que a escola, como uma das instituições presentes na sociedade, constitua-se num espaço dinamizador da esfera da produção capitalista, sistema hegemônico, fazendo com que 0 trabalho do professor assuma características de alienação (FRIZZO, 2008b).

Para Marx (2001), a alienação do trabalho tem como vertente as leis da economia política do sistema capitalista, sendo proporcional ao desenvolvimento da sociedade. Em outras palavras, isso significa dizer que quanto mais a sociedade se desenvolve, mais o trabalhador se torna dependente do modelo hegemônico. $O$ trabalho do professor não é diferente, o que demonstra que a organização do trabalho pedagógico na escola capitalista, atualmente, apresenta-se desvinculada da prática social, caracterizada pela fragmentação, alienação e ausência do trabalho material (FREITAS, 2012).

O conceito de trabalho pedagógico se refere a todo trabalho realizado pelo professor na escola numa visão mais ampla, não restrito ao contexto da aula, considerando também as articulações entre estruturas sociais, políticas, econômicas e a realidade da docência na escola (FRIZZO, 2008a). Desse modo, entende-se que não há como pensar o trabalho pedagógico da Educação Física sem considerar os contextos históricos e sociais da escola.

O trabalho pedagógico, na concepção do materialismo histórico dialético, visa à emancipação tanto do aluno quanto do trabalho realizado pelo professor, tendo como finalidade a produção de conhecimento '[...] por meio do trabalho com valor social (não do 'trabalho' de faz de conta, artificial); a prática refletindo-se na forma de teoria que é devolvida à prática, num circuito indissociável e interminável de aprimoramento" (FREITAS, 2012, p. 100, grifo do autor). No entanto, percebe-se, atualmente, que o trabalho pedagógico está descaracterizado, regulamentado e burocratizado, fortalecendo as relações de poder e da classe dominante (RIBAS; FERREIRA, 2014).

Para Taffarel et al. (2006), o trabalho pedagógico na Educação Física tem como objeto a Cultura Corporal. A apropriação desse conhecimento ocorre com ênfase na justiça social, na transformação da sociedade, na contextualização e resgate dos fatos e do conhecimento histórico, fazendo do aluno um sujeito crítico, histórico, social e emancipador. Além disso, Ribas e Ferreira (2014) destacam que o trabalho pedagógico do professor de Educação Física é entendido como práxis pedagógica, superando a dicotomia entre teoria e prática, a partir das categorias centrais do materialismo histórico dialético.

A práxis pode ser concebida como uma relação dialética, caracterizada pela contradição, tensão entre teoria e prática. É nessa relação dialética que a compreensão da realidade tem sentido, ao retornar para a mesma realidade buscando sua transformação, sendo que a concretização da práxis é capaz de transformar o ser humano e o meio em que vive (SÁNCHEZ GAMBOA, 1995).

O trabalho pedagógico, de acordo com Freitas (2012), apresenta categorias centrais que estão diretamente interligadas, como, por exemplo, os pares dialéticos objetivo/avaliação e conteúdo/método. Para o autor, a avaliação é a guardiã dos objetivos. Desse modo, o professor deve ser coerente com sua proposta, ou seja, a avaliação deve estar coesa em relação aos objetivos que ele pretende atingir. Outra categoria se refere ao conteúdo/método, que deve ser condizente com a proposta de seus objetivos. Essas categorias caracterizam e estruturam a organização do trabalho pedagógico do professor na escola. Por conseguinte, elas auxiliam 
a identificar a escola como uma instituição que reproduz em seus objetivos/avaliação a subordinação advinda do sistema capitalista (FREITAS, 2012).

A organização do trabalho pedagógico na escola, segundo Freitas (2012), envolve diferentes elementos que a constituem, como sua realidade, seus fatores históricos, métodos, objetivos e didática. A partir do exposto, pressupõe-se que o conhecimento da Cultura Corporal poderá considerar os fundamentos da Praxiologia Motriz, para constituir, com maior clareza, a organização do trabalho pedagógico e da didática.

A didática, enquanto área de conhecimento na formação do professor, apresenta como objeto de estudo o ensino. Ela deverá refletir na teoria e na prática pedagógica uma proposta que busca transformar o ensino, empenhando-se na luta por novas relações de trabalho na sociedade (OLIVEIRA, 1992). A didática pode ser definida como:

[...] uma área da Pedagogia, que pesquisa a práxis pedagógica, suas condições e modos de realização, de forma a atingir os objetivos do ensino. Embora a realização do processo escolar ocorra, principalmente, em sala de aula, seu objetivo é ultrapassar esse espaço, uma vez que os alunos apropriando-se dos conhecimentos sistematizados atuarão de forma diferenciada no meio social em que vivem (PIMENTA, 2009, p. 8).

Segundo Oliveira (1988), a didática não englobaria somente 0 ato didático, como também conteúdo, método, planejamento e avaliação. A autora destaca que a didática deve ser compreendida no movimento desses elementos, a partir de sua totalidade, envolvendo dimensões histórica, antropológica, ideológica e epistemológica.

A didática abrange os conhecimentos relativos à metodologia, que engloba os métodos e as técnicas de ensino. Pimenta (2009) aponta a metodologia como estudo dos métodos, sendo estes um conjunto de regras fundamentais para o ensino de um conteúdo, atrelado à teoria pedagógica, com a finalidade de atingir objetivos. As técnicas de ensino são recursos operacionais e didáticos dos métodos de ensino, sendo as técnicas utilizadas como meio desse processo.

A concepção didática que fundamenta essas reflexões advém da Pedagogia HistóricoCrítica, de Dermeval Saviani, sendo esta a "[...] concepção que procura compreender e explicar o todo deste processo, abrangendo desde a forma como são produzidas as relações e suas condições de existência até a inserção da educação neste processo" (SAVIANI, 2005, p. 141). A didática baseada na Pedagogia Histórico-Crítica deve se constituir como área do conhecimento que se concretiza a partir de uma concepção de ser humano, sociedade e mundo, e não está limitada a métodos e técnicas de ensino.

A didática, na referida perspectiva, desenvolve-se em cinco momentos: 1º) Prática Social: esse é o ponto de partida comum entre professor e aluno, porém, o aluno apresenta uma visão sincrética, desordenada do conteúdo, de senso comum, e o professor possui uma síntese precária em relação ao conhecimento do aluno, pois, apesar de possuir conhecimentos sistematizados, "[...] a prática social envolve uma antecipação do que lhe será possível fazer com alunos cujos níveis de compreensão ele não pode conhecer no ponto de partida, senão de forma precária" (SAVIANI, 2009 p. 63); 2º) Problematização: refere-se ao momento de detectar questões postas pela prática social e os conhecimentos necessários para resolvê-las; $3^{\circ}$ ) 
Instrumentalização: são as ações, instrumentos, atividades e recursos didático-pedagógicos para o processo de aprendizagem, de modo que o aluno incorpore os conhecimentos científicos; $\left.4^{\circ}\right)$ Catarse: é a síntese do processo; refere-se à apropriação do conhecimento, no qual o aluno expressa a compreensão e conclusão do conhecimento proposto; $5^{\circ}$ ) Prática Social: é definida, agora, como ponto de chegada, sendo o momento em que 0 aluno atinge 0 nível de entendimento mais elaborado em relação ao ponto de partida, sendo a prática social alterada de forma qualitativa, possibilitando ao aluno compreender e agir sobre a realidade (SAVIANI, 2009).

Para Freitas (2012), a teoria educacional e a teoria pedagógica são elementos essenciais que servem de referência para a organização do trabalho pedagógico do professor na escola. Para o autor, a teoria educacional é a didática que dá sentido a todos os processos pedagógicos utilizados pelo professor, enraizada numa concepção de educação centralizada em um projeto histórico, nas relações estabelecidas entre sociedade e educação e na objetivação de qual sujeito se pretende formar. A teoria pedagógica se refere diretamente ao trabalho pedagógico desenvolvido pelo professor frente aos alunos e como a organização do trabalho pedagógico na escola se materializa.

Parlebas (1991) também situa a didática da Educação Física que, no contexto francês, vem ocupando espaço de um corpo de conhecimento que trata de todos os processos realizados durante uma situação de ensino, ou seja, uma concepção pedagógica. $\mathrm{O}$ autor afirma que a lógica interna das práticas corporais se constitui em uma das contribuições da Praxiologia Motriz para a organização didática na Educação Física.

\section{PRAXIOLOGIA MOTRIZ}

Pierre Parlebas desenvolveu os fundamentos praxiológicos a partir de conceitos consolidados em disciplinas científicas como a Sociologia, a Antropologia e a Matemática. Os jogos e esportes são manifestações sociais e da humanidade, por isso, deveriam ser entendidos nessa perspectiva. A Ação Motriz, unidade básica das manifestações da Cultura Corporal, é considerada um tipo de ação social, teoria desenvolvida por Talcott Parsons ${ }^{1}$ e aprofundada por outros sociólogos. Parlebas, porém, delimitou essa ação social no jogo e no esporte. 0 que surge dessas ações sociais específicas do jogo/esporte ${ }^{2}$, que são escritas pelas regras do jogo, é a Ação Motriz. A partir desta premissa, o autor desenvolveu instrumentos conceituais que colocam em evidência a lógica de cada jogo, os organiza num sistema de classificação e nos Universais, que serão abordados mais adiante.

Outra importante influência teórica da Praxiologia Motriz, e talvez a mais forte, refere-se à linguística estrutural de Ferdinand de Saussure ${ }^{3}$. Este âmbito trata de estudar as estruturas das comunicações orais e escritas, ou seja, as invariantes que ocorrem nas formas de comunicação, estabelecendo com isso uma gramática. Pierre Parlebas, de forma mais pontual

\footnotetext{
1 Sociólogo norte-americano que propôs a teoria da ação social que visava constituir uma teoria geral para a análise da sociedade. Pierre Parlebas apropriou-se do conceito de ação social e desenvolveu o conceito de Ação Motriz como unidade de análise dos jogos e esportes.

2 Mais adiante no texto, ao abordar os conteúdos da Educação Física, substituiremos jogos e esporte por Manifestações da Cultura Corporal.

3 Linguista e filósofo suíço, Parlebas se apropriou de sua obra ao tratar da Semiótica.
} 
nas manifestações dos jogos e esportes, criou instrumentos que possibilitam a criação de um vocabulário científico para essas manifestações.

Parlebas (2001), no prefácio de sua obra mais completa, mostra que existem muitos equívocos de descrição, classificação e, consequentemente, de entendimento relativo às dinâmicas dos jogos e esportes - por exemplo, afirmar que o judô ou qualquer outro tipo de prática de combate similar é uma atividade física do tipo individual. 0 olhar praxiológico nos revela que, em sua essência, as informações oriundas do adversário são fundamentais para 0 êxito dos praticantes. Com isso, sequências de golpes, velocidade e explosão são elementos importantes, mas a essência está na escolha do melhor golpe em função da ação do adversário. É um constante processo de leitura e formulação de estratégias e processos de tomadas de decisões para superar o adversário. $O$ entendimento dos sentidos das ações motrizes, de forma criteriosa, é que permite a elaboração de uma gramática do jogo. As regras do jogo regem a dinâmica da atividade, e o estudo de suas ações motrizes, à luz da Praxiologia Motriz, decifra e constrói sua gramática.

Desse modo, enfatizaremos alguns conceitos e fundamentos essenciais que derivam da Praxiologia Motriz. Segundo Lagardera Otero e Lavega Burgués (2008, p. 59), "[...] a Praxiologia Motriz pretende estudar as ações motrizes que emergem em qualquer situação esportiva ou lúdica, como consequência de uma complexa trama de relações que se estabelecem entre os participantes, independente de quem sejam estes".

A Praxiologia Motriz consiste numa ciência que tem como objeto de estudo a Ação Motriz. Parlebas (2014, p. 12) afirma que a ciência da Ação Motriz se concretiza sobre "[...] os elementos concretos e controláveis, sobre os traços da lógica externa e que demonstram as relações que ocorrem entre os praticantes com seus adversários e seus companheiros, com espaço e objetos e com as pressões do tempo".

Desse modo, a Praxiologia Motriz está centrada no estudo da lógica interna dos jogos e esportes sem desconsiderar a lógica externa. A lógica interna é a estrutura lógica que constitui cada jogo e esporte, dos protagonistas e agentes ativos evolvidos e de suas regras. Por exemplo, a lógica interna de um jogo de basquetebol da NBA será a mesma de uma partida de jovens que estão aprendendo o esporte, desde que as regras sejam as mesmas (RIBAS, 2002).

O Sistema de Classificação, um dos instrumentos de análise da Praxiologia Motriz, constitui-se na organização dos jogos e esportes a partir de critérios relativos à lógica interna, e não no número de jogadores ou tipos de materiais. O CAl ${ }^{4}$, forma como é conhecido o Sistema de Classificação, está sistematizado a partir de dois critérios: o entorno físico e a interação entre os participantes. $O$ entorno físico é classificado como padrão, que não requer leitura do meio, e incerto, que exige constante leitura do meio físico. No que se refere às interações entre participantes, pode-se destacar a interação de cooperação, oposição e cooperação-oposição, grupos de atividades denominadas como sociomotriz. As atividades sem interação entre os participantes são denominadas psicomotrizes. Considerando esses dois critérios, Parlebas chegou a oito categorias do CAl, conforme figura abaixo: 
Figura 1 - Sistema de Classificação

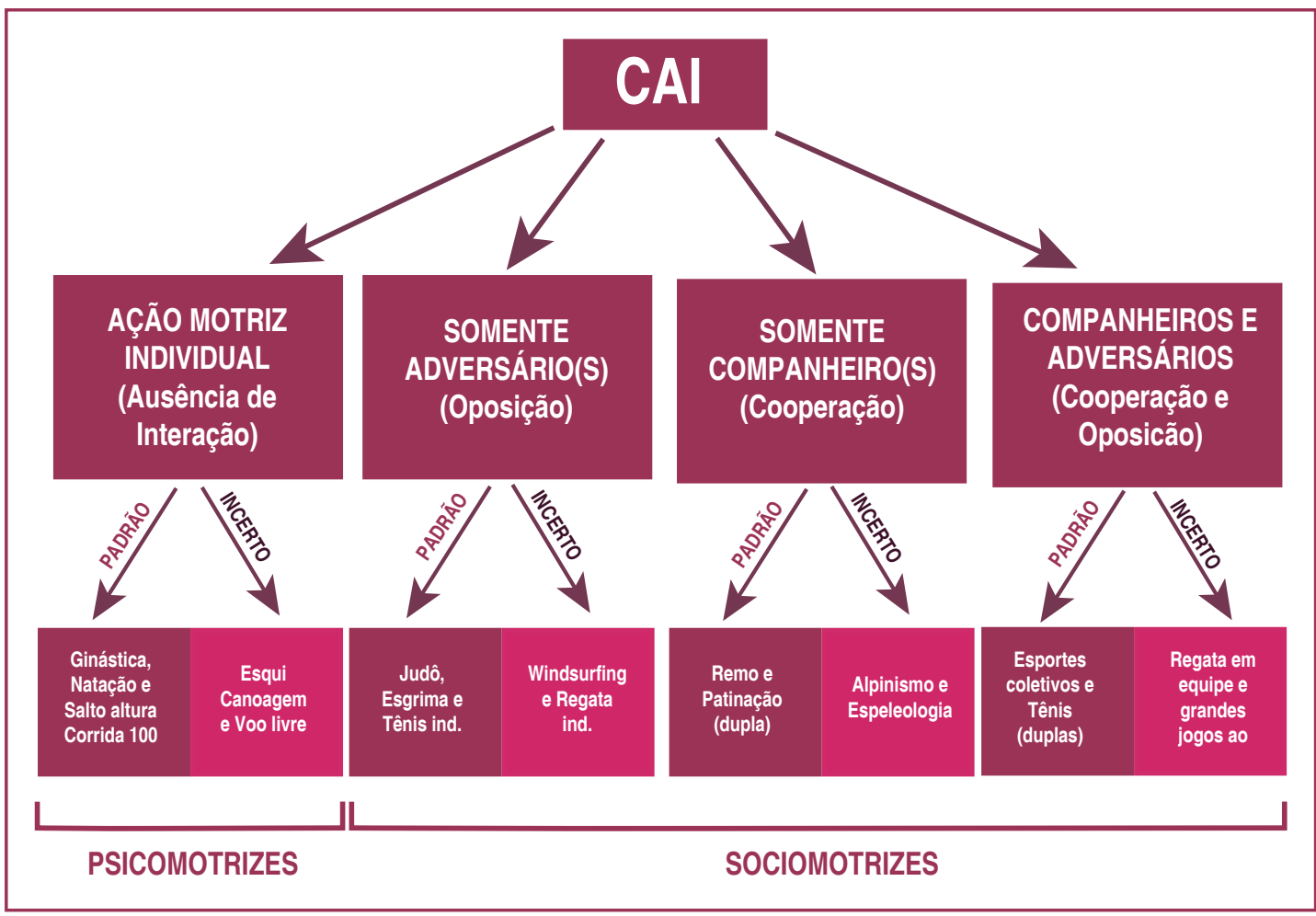

Fonte: Figura de Parlebas (1987, p. 18) adaptada pelos autores.

Os Universais, para Parlebas (2001, p. 463), são "modelos operativos que representam as estruturas básicas do funcionamento de todo jogo esportivo e que constituem sua lógica interna". Esses elementos aprofundam o entendimento do funcionamento do jogo, sendo estes a comunicação práxica (redes de comunicação), os gestemas e praxemas e os papéis e subpapéis.

Parlebas (2001) intitula os conteúdos da Educação Física como um conjunto de situações motrizes. $O$ autor agrupa as Grandes Situações Motrizes em quatro conjuntos:

a) jogos esportivos institucionalizados (esportes) - situações motrizes competitivas, institucionalizadas, com regras bem definidas, alinhadas ao sistema capitalista;

b) jogos esportivos tradicionais - situações motrizes competitivas ou não, caracterizadas por um contexto regional ou local, e que normalmente não apresentam fortes influências políticas, econômicas e mercadológicas;

c) exercícios didáticos - situações motrizes sistematizadas por objetivos didáticos para 0 desenvolvimento corporal, como, por exemplo, ioga, relaxamento, treinamento e expressão corporal;

d) atividades livres - situações motrizes nas quais o praticante atua com liberdade, flexibilidade e sem obrigações codificadas e predeterminadas, normalmente realizadas na natureza.

A lógica externa está associada à compreensão do contexto sociocultural em que as manifestações estão inseridas, por exemplo, questões relacionadas à mídia, violência, política, economia no contexto esportivo, podendo este assumir diferentes sentidos. Parlebas (2001, p. 307) afirma que "Cada pessoa e cada grupo social pode reinterpretar as práticas a sua forma, segundo suas aspirações e suas motivações". Nesse artigo, a lógica externa está sustentada 
na Pedagogia Histórico-Crítica/Crítico-Superadora. Toda a organização didática, metodológica e as técnicas de ensino se dariam a partir dessa orientação. E a Praxiologia Motriz, onde estaria situada?

A Praxiologia Motriz, por um lado, vem consolidando cada vez mais seus instrumentos científicos de olhar para as manifestações da Cultura Corporal a partir da lógica interna. Por outro, as concepções críticas de educação consideram central a necessidade de realizar um trabalho pedagógico sustentado na práxis. Assim, faz-se necessário possibilitar uma educação ampliada, articulada teoricamente, com métodos mais criteriosos, visando a uma sociedade mais justa, livre do senso comum e pautada no conhecimento científico, neste caso o conhecimento da Praxiologia Motriz.

\section{APROXIMAÇÃO ENTRE PRAXIOLOGIA E A PEDAGOGIA HISTÓRICO-CRÍTICA}

O primeiro aspecto a ser tratado é a relação estabelecida entre a lógica externa, representada pelas características da Pedagogia Histórico-Crítica, e a lógica interna da Praxiologia Motriz, aprofundando os conhecimentos da área, a partir da Ação Motriz e da formação humana. O GEP Brasil vem centrando seus estudos no tema da Praxiologia Motriz, mas não de forma neutra. Esse grupo de pesquisa se constitui a partir de uma concepção filosófica, pedagógica e, consequentemente, de Educação Física. Há algum tempo, são discutidas questões relativas ao materialismo histórico dialético junto com colegas de outros grupos de pesquisa, os quais apontam a necessidade de instrumentalizar o olhar científico para a proposta de sociedade que vem sendo constituída pelas forças do sistema capitalista. Essa perspectiva aponta para uma proposição pedagógica mais crítica no sentido de superar e transformar o sistema vigente.

Na Educação, em meados da década de 1980, um grupo de pesquisadores da Educação brasileira, liderados por Saviani, propôs a Pedagogia Histórico-Crítica. Na Educação Física, nesse mesmo período, também influenciada por esse grupo, surgiu a proposta da abordagem Crítico-Superadora. A Pedagogia Histórico-Crítica aponta princípios didáticos e metodológicos para a Educação, ou seja, materializa a intencionalidade pedagógica referente à lógica externa. A partir de quais critérios esta proposta pedagógica poderia sistematizar conteúdos da Educação Física; transferir lógica de jogos e esportes; propor critérios metodológicos consistentes e coerentes?

Estudos como o de Ribas (2010) explicam que a Praxiologia Motriz apresenta, de forma original e consistente, novos horizontes para essas questões. Em síntese, o autor mostra que a teoria da Ação Motriz agrega importantes conhecimentos científicos das manifestações da Cultura Corporal que poderão sustentar o trabalho pedagógico do professor para:

- Compreender e identificar melhor a essência das manifestações - O que é mais importante ensinar no voleibol? Quais os conhecimentos dessa modalidade? Qual o melhor método de ensino?

- Transferir lógicas de uma manifestação da Cultura Corporal para a outra - O que aproxima o futebol do basquetebol? Quais conceitos? Quais as diferenças? Quais as ações motrizes são mais relevantes e essenciais? Por que alguns alunos têm facilidade e outros não? 
- Consistência e sentido - Discutir a violência social; Ensino de práticas solidárias; Que características tem a competição na sociedade atual? A cooperação, o coletivo e a sociedade capitalista?

- Organizar e selecionar conteúdos - Como estão organizados nossos programas de Educação Física? Por que não estamos contemplando os jogos tradicionais e populares? As atividades psicomotrizes e de oposição não deveriam fazer parte dos programas de Educação Física?

Em outro estudo, Ribas (2002) aprofundou a análise dos Parâmetros Curriculares Nacionais que investigou as manifestações da Cultura Corporal propostas nesse documento. Os resultados do estudo indicam que as relações entre lógica interna e lógica externa estavam bastante incoerentes neste documento, assim como foi identificada a falta de cuidado com o conhecimento dos jogos tradicionais. Por outro lado, 0 autor mostrou que o esporte segue prevalecendo nos conteúdos, e sugere a incorporação dos conceitos originados do Sistema de Classificação e das Grandes Situações Motrizes no processo de sistematização de conteúdos para a Educação Física.

É na lógica interna dos jogos e esportes que Pierre Parlebas vem situando a Praxiologia Motriz, campo epistemológico que, segundo o autor, identifica a nossa área de conhecimento. 0 professor de matemática entende de lógica interna dos distintos conhecimentos da matemática. $O$ de português pauta seu trabalho pedagógico na gramática. $O$ de música, na estrutura e teoria musical. A Educação Física, a partir dos critérios e instrumentos da Praxiologia Motriz, ocupa-se da lógica interna das manifestações da Cultura Corporal.

Na organização do trabalho pedagógico deve-se levar em consideração tanto os aspectos da lógica interna como os da externa, pois ambos possibilitam o entendimento para o ensino da Educação Física. Toda e qualquer manifestação da Cultura Corporal é provida minimamente de regras. A partir dessa regulamentação é possível identificar, classificar, elencar e compreender os elementos centrais que caracterizam cada manifestação. Entretanto, a lógica interna não é suficiente para apresentar o sentido social ou significado atribuído às manifestações da Cultura Corporal. Esses elementos são evidenciados na concepção pedagógica, ou seja, concepção de mundo, sociedade, ensino, Educação Física. Dessa forma, as manifestações da Cultura Corporal são compostas por conhecimentos relativos à lógica interna e pelo sentido social atribuído pela Pedagogia Histórico-Critica, configurando a lógica externa.

Outro aspecto a ser considerado é a relação estabelecida entre a Cultura Corporal e as Grandes Situações Motrizes. A Cultura Corporal, segundo Soares et al. (2012), trata os jogos, os esportes, as danças, as lutas e a ginástica como conteúdos da Educação Física. 0 objetivo é a expressão corporal como linguagem, na qual "[...] o homem apropria-se da Cultura Corporal dispondo sua intencionalidade para o lúdico, o artístico, o agonístico, o estético ou outros, que são representações, ideias, conceitos produzidos pela consciência social", sendo essas as "significações objetivas" (SOARES et al., 2012, p. 62). Ainda segundo os autores, os temas tratados na Educação Física expressam "um sentido/significado onde se interpenetram, dialeticamente, a intencionalidade/objetivos do homem e as intenções/objetivos da sociedade". Para a Praxiologia Motriz, os conhecimentos que tratam da Educação Física são representados a partir das Grandes Situações Motrizes, sendo eles os jogos, os esportes, os exercícios didáticos e as atividades livres (PARLEBAS, 2001). 
Os conteúdos classificados por Soares et al. (2012) poderão ser reorganizados a partir da perspectiva da teoria da Ação Motriz, mais especificamente, com base nas Grandes Situações Motrizes da Educação Física. Por exemplo, a ginástica pode ser um jogo tradicional (atividade circense), esporte (ginástica artística ou ginástica rítmica) ou um exercício didático (ginástica de academia) de acordo com a classificação de Parlebas (2001). Assim, sugere-se a incorporação das Grandes Situações Motrizes para caracterizar as manifestações da Cultura Corporal, contribuindo com o trabalho pedagógico e a Didática da Educação Física, proposta que adotaremos nos próximos estudos.

A abordagem Crítico-Superadora sistematiza os conhecimentos por: relevância social dos conteúdos, contemporaneidade e adequação às características sociocognoscitivas dos alunos. Em relação a esses critérios, poderíamos projetar a Praxiologia Motriz questionando a ausência de determinados grupos de situações motrizes, ao mesmo tempo em que poderíamos identificar lacunas de manifestações culturais a partir do Sistema de Classificação. Em relação ao primeiro aspecto, observa-se que os programas de Educação Física atualmente não vêm contemplando os jogos tradicionais, populares ou de ruas, assim como as atividades livres em plena natureza. Os esportes sempre aparecem como orientações centrais dos programas de Educação Física.

Em relação ao sistema de classificação, limitar-nos-emos a discutir a crítica mais corrente da Educação Física: o predomínio dos Jogos Esportivos Coletivos. Significa que as aulas de Educação Física limitam as experiências corporais a um grupo de manifestações com características de cooperação e oposição. Conforme a Figura 1, o Sistema de Classificação é composto por oito grupos. Ribas (2010) sugere que os programas contemplem os quatro grupos relativos à interação (cooperação, oposição, cooperação-oposição e sem interação/ psicomotriz), somados ao grupo de manifestações culturais com características da incerteza em relação ao meio de prática. Esses conceitos deverão orientar o processo de organização de currículos (Estados e Municípios), projetos políticos pedagógicos e planejamento do professor. A Praxiologia Motriz, desta forma, possibilita novos critérios para sistematizar os conhecimentos da Educação Física com base nas Grandes Situações Motrizes e no Sistema de Classificação.

É importante mencionar que em 2009 foi publicado o Referencial Curricular de Educação Física, no qual os autores González e Fraga (2009) apresentaram uma proposta de referenciais curriculares para a Educação Física. $O$ documento, resultado de um vasto trabalho intelectual, com a colaboração de professores que atuavam em redes de ensino no Estado do Rio Grande do Sul, apresenta importantes contribuições para a Educação Física e contempla conceitos da Praxiologia Motriz: Sistema de Classificação e Grandes Situações Motrizes da Educação Física. Porém, com a mudança de governo, infelizmente, os passos seguintes de implementação dessa proposta na rede estadual não foram suficientemente consolidados, como exemplo, formação continuada e avaliação da proposta. Mesmo diante dessas limitações, cabe destacar que o Estado do Rio Grande do Sul tem um documento concreto, com bases científicas com a contribuição de professores, para pensar os novos caminhos para nossa área no contexto do Rio Grande do Sul.

Para Araújo, Souza e Ribas (2014), a relação da Praxiologia Motriz com a Pedagogia Histórico-Crítica/Crítico-Superadora poderá ser materializada na instrumentalização, a partir 
dos cinco passos de Saviani. Nesta proposta teórico-metodológica, a Praxiologia Motriz possibilita aos alunos o entendimento da lógica interna de uma determinada manifestação da Cultura Corporal, possibilitando o aprofundamento neste conhecimento.

A prática social, ponto de partida e de chegada dos cinco passos de Saviani, indica a necessidade de um conhecimento concreto a ser tratado, e, ao final, que esse conhecimento seja ampliado e entendido em sua totalidade, o que significa vincular os conteúdos específicos com as finalidades sociais mais amplas. $O$ conhecimento, além de ser considerado em sua totalidade, deverá ser situado na especificidade da Educação Física, ou seja, jogo, esporte, exercícios didáticos e atividades livres. No passo da problematização, de acordo com Saviani (2005), identificam-se os aspectos que precisam ser resolvidos no que tange à prática social. Um desses aspectos se refere à própria lógica interna da Cultura Corporal em questão. Como exemplo: características centrais, elementos que constituem a manifestação, aprendizados e limitações para participar do jogo. 0 outro aspecto diz respeito à lógica externa, como: condições materiais para o aprendizado, características contextuais da manifestação, lesões, aspectos biomecânicos, dentre outros.

No processo de instrumentalização é que reside o ápice do conhecimento praxiológico, para que 0 aluno se aproprie dos conteúdos socialmente produzidos e culturalmente preservados. Vivenciar as manifestações da Cultura Corporal com conceitos e parâmetros de entendimento consistentes em relação à lógica interna constitui-se no objeto central da proposta de Parlebas. Isto significa superar conceitos e classificações que não contemplem entendimento criterioso das manifestações, levando a confusões como: classificar jogos e esportes a partir de materiais ou espaços (jogos com bola, esportes aquáticos), propor jogos de cooperação com características de oposição, entre outros.

A catarse significa não só entendimento da lógica interna e externa, mas as relações entre elas. A cooperação, por exemplo, evidenciada em algumas manifestações esportivas, jogos tradicionais, atividades livres e exercícios didáticos, deve ser compreendida no seu contexto e, para além deste, como uma prática social. Nesse viés, questões poderão emergir: A quem serve essa cooperação? Em qual contexto social ela se produz? Por que cooperamos?

Os instrumentos de análise e interpretação da lógica interna propostos pela Praxiologia Motriz têm sido objeto de estudo e aprofundamento em modalidades específicas. Um jogo coletivo, com características de cooperação e oposição, normalmente tem sido entendido, na atualidade, a partir de suas técnicas, como, por exemplo, o toque e a manchete no voleibol. Ribas (2014), em seu estudo sobre esta modalidade, apresenta novos conhecimentos que compõem o entendimento e, consequentemente, o ensino do voleibol. Nessa perspectiva, 0 toque e a manchete assumem sentidos diferentes considerando o momento e as interações do jogo. O toque pode ser realizado a partir da interação de oposição buscando uma cooperação, como acontece na recepção, ou, essencialmente cooperativo, como acontece na situação do levantamento. Esses novos conhecimentos constatados pelo autor, e possíveis de serem identificados por meio do olhar praxiológico, deverão ser considerados na organização didática, metodológica e, por conseguinte, nas técnicas de ensino. Na figura abaixo se estabelece a aproximação entre a Pedagogia Histórico-Crítica/Crítico-Superadora e a Praxiologia Motriz. 
Figura 2 - Aproximações da lógica externa - Pedagogia Histórico-Crítica com a lógica interna - Praxiologia Motriz

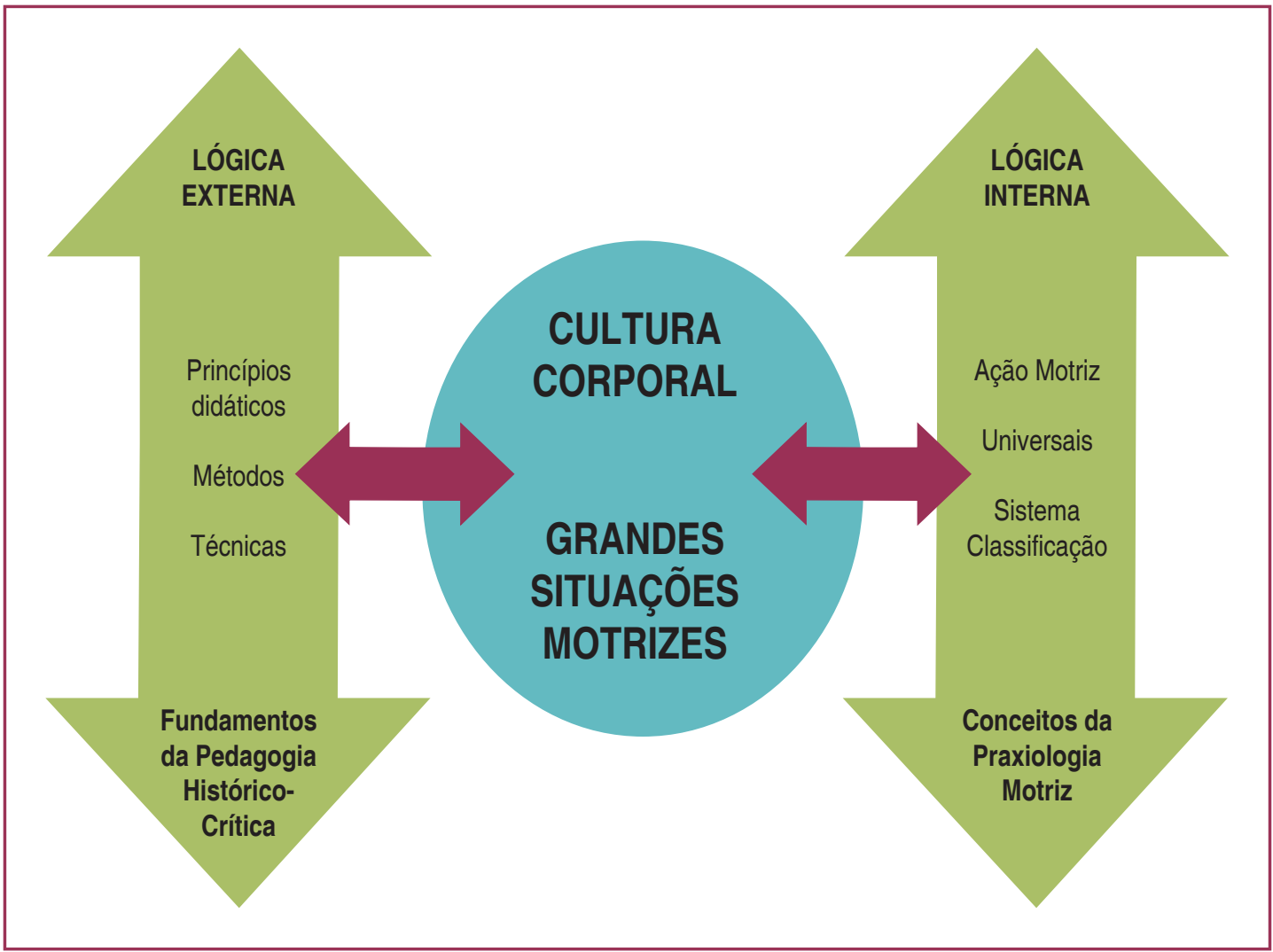

Fonte: Os autores (2016)

\section{CONSIDERAÇÕES FINAIS}

A Pedagogia Histórico-Crítica vem consolidando cada vez mais os pilares pedagógicos de uma concepção contra-hegemônica. Esta perspectiva indica, com bastante objetividade e clareza, parâmetros para a organização do trabalho pedagógico e da didática, possibilitando um entendimento mais amplo da prática social. De forma mais específica no campo da Educação Física, Parlebas, com o olhar da Praxiologia Motriz, colabora com a organização do conhecimento das Grandes Situações Motrizes que identifica quatro grandes grupos da Cultura Corporal. Três grupos se relacionam com as manifestações culturais produzidas e consolidadas pelo processo histórico da humanidade, no caso, os esportes, os jogos tradicionais e as atividades livres. Os exercícios didáticos estão mais relacionados ao campo técnico, acadêmico e científico da Educação Física. Temos aqui um criterioso detalhamento de distintos âmbitos e origens das manifestações da Cultura Corporal.

No momento em que o professor estiver diante de um conteúdo das manifestações da cultura corporal, constata-se que este olhar pode ser enriquecido com instrumentos mais sólidos que desvelam a lógica interna. Isso consiste em compreender a dinâmica de funcionamento e os elementos que se destacam para se desdobrar em novos objetos de ensino, como é o caso dos esportes de interação. Cada contexto irá apresentar a sua história, mas a lógica interna da manifestação da Cultura Corporal não se altera, se as regras da manifestação em questão se mantiverem inalteradas. 
Estes dois aspectos articulados, a pedagogia Histórico-Crítica e a Praxiologia Motriz, não podem ser entendidos como etapas ou instâncias, mas, sim, como âmbitos do conhecimento que deverão estar articulados em um processo dialético. Os princípios pedagógicos e didáticos indicados pela Pedagogia Histórico-Crítica deverão aproximar-se da Educação Física através da Cultura Corporal. Qualquer que seja a manifestação da Cultura Corporal é possível compreendê-la por sua lógica interna. 0 movimento de retorno à prática social passará por retomar as técnicas, os métodos, a didática e os pilares da proposta pedagógica, verificando neste movimento a coerência interna do trabalho pedagógico. Esta aproximação é de extrema relevância, pois aponta novos conhecimentos para trabalho pedagógico e da didática das manifestações da Cultura Corporal, consolidando cada vez mais a prática social da Educação Física.

\section{REFERÊNCIAS}

ARAUJO, Pablo Aires; SOUZA, Maristela da Silva; RIBAS, João Francisco Magno. Praxiologia motriz e a abordagem crítico-superadora: aproximações preliminares. Motricidade, v. 10, n. 4, p. 3-15, 2014. Disponível em: <http://revistas.rcaap.pt/motricidade/article/view/2658>. Acesso em: 19 set. 2015.

FREITAS, Luiz Carlos de. Crítica da organização do trabalho pedagógico e da didática. 11. ed. Campinas, SP: Papirus, 2012.

FRIZZO, Giovanni Felipe Ernst. O trabalho pedagógico como referência para a pesquisa em Educação Física. Pensar a Prática, v. 11, n. 2, p. 159-167, 2008a.

FRIZZO, Giovanni Felipe Ernst. Trabalho pedagógico: conceito central no trato do conhecimento da pesquisa em educação. Trabalho Necessário, v. 6, n. 6, 2008b. Disponível em: <http://www.uff.br/ trabalhonecessario/images/TN06FRIZZO,G.pdf>. Acesso em: 16 jan. 2015.

GONZÁLEZ, Fernando Jaime; FRAGA, Alex Branco. Referencial curricular de educação física. In: RIO GRANDE DO SUL. Secretaria de Estado da Educação. Departamento Pedagógico. (Org.). Referências curriculares do estado do Rio Grande do Sul: linguagens, códigos e suas tecnologias. Porto Alegre, 2009. v. 2, p. 112-181.

LAGARDERA OTERO, Francisco; LAVEGA BURGUÉS, Pere. Fundamentos da Praxiologia Motriz. In: RIBAS, J. F. M. (Org.). Jogos e esportes: fundamentos e reflexões da praxiologia motriz. Santa Maria: UFSM, 2008. p. 45-79.

MARX, Karl. Manuscritos econômicos e filosóficos. São Paulo: Martin Claret, 2001.

OLIVEIRA, Maria Rita Neto Sales. A reconstrução da didática: elementos teórico-metodológicos. Campinas: Papirus, 1992.

OLIVEIRA, Maria Rita Neto Sales. 0 conteúdo da didática: um discurso da neutralidade científica. Belo Horizonte: UFMG, 1988.

PARLEBAS, Pierre. Didactique et logique interne des aps. Revue EPS, n.228, p. 23-28, 1991.

PARLEBAS, Pierre. Juegos, deportes y sociedades: léxico de praxiología motriz. Tradução de Fernando Gonzáles del Campo Román. Madrid: Paidotribo, 2001. 
PARLEBAS, Pierre. Prefácio. In: RIBAS, João Francisco Magno (Org.). Praxiologia motriz e voleibol: elementos para o trabalho pedagógico. ljuí: Unijuí, 2014. p. 11-13.

PIMENTA, Viviane Ziemmer Magalhães. Desafios da didática na perspectiva da pedagogia histórico-crítica. 2009. Disponível em: <http://www.gestaoescolar.diaadia.pr.gov.br/arquivos/File/ producoes pde/artigo viviane ziemmer magalhaes.pdf>. Acesso em: 19 set. 2015.

RIBAS, João Francisco Magno. Contribuições da Praxiologia Motriz para a Educação Física escolar- Ensino Fundamental. 2002. 256f. Tese (Doutorado em Educação Física), Faculdade de Educação Física, Universidade Estadual de Campinas. Campinas, SP, 2002.

RIBAS, João Francisco Magno. O voleibol e os novos olhares dos jogos esportivos coletivos. In: RIBAS, João Francisco Magno (Org.). Praxiologia motriz e voleibol: elementos para o trabalho pedagógico. ljuí: Editora Unijuí, 2014.p. p. 21-56.

RIBAS, João Francisco Magno; FERREIRA, Liliana Soares. O trabalho de professores de Educação Física e de pedagogos na escola como práxis pedagógica. Movimento, v. 20, n. 1, p. 125-143, jan./ mar. 2014.

RIBAS, João Francisco Magno; OLIVEIRA, Gil Teixeira. Articulações da praxiologia motriz com a concepção crítico-emancipatória. Movimento, v. 16, n. 1, p.131-148, 2010.

SANCHÉZ GAMBOA, Silvio. Teoria e da prática: uma relação dinâmica e contraditória. Motrivivência, n. 8, p. 31-45, dez. 1995.

SAVIANI, Dermeval. Pedagogia Histórico-Crítica: primeiras aproximações. 9. ed.. Campinas- São Paulo. Autores Associados, 2005. (Coleção Educação Contemporânea).

SAVIANI, Dermeval. Escola e democracia. 41. ed. ed. rev. Campinas, SP: Autores Associados, 2009.

SOARES, Carmen Lúcia et al. Metodologia do ensino da Educação Física. São Paulo: Cortez, 2012.

TAFFAREL, Celi Nelza Zulke et al. Formação de Professores de Educação Física para a cidade e 0 campo. Pensar a Prática, v. 9, n. 2, p. 153-179, jul./dez. 2006. 